\title{
The readiness of Small and Medium-sized Enterprises (SMEs) for the digitalization of industry: Evidence from the Czech Republic
}

\author{
Vladimír KRAJČÍK ${ }^{1}$
}

Authors' affiliations and addresses:

${ }^{1}$ University of Business and Law

Spálená 14 Prague, Czech Republic

e-mail: krajcik@vso-praha.eu

Funding information:

Technology Agency of the Czech Republic

Grant Number TB95TACR999

\section{Acknowledgement: \\ This research is a part of the scientific research project "Návrh perspektiv tematických oblastí výzkumu, vývoje a inovací reagujících na kontext, obsah a rozsah průmyslové revoluce (Průmysl 4.0, 5.0)" funded by the Technology Agency of the Czech Republic TAČR.}

How to cite this article:

Krajčík, V. (2021). The readiness of Small and Medium-sized Enterprises (SMEs) for the digitalization of industry: Evidence from the Czech Republic. Acta Montanistica Slovaca, Volume 26 (4), 761-772.

DOI:

https://doi.org/10.46544/AMS.v26i4.13

\begin{abstract}
This paper examines the introduction of elements and processes of the digital economy in SMEs in the Czech Republic. The article analyses the factors of their preparedness for the digitization of industry in the context of changes in the global economy, and it scrutinizes the principal advantages, shortcomings, opportunities and obstacles that SMEs perceive in preparing and implementing changes in line with the Industry 5.0 initiative. The research into this preparedness was carried out in the form of both a questionnaire survey and semi-structured interviews. They were conducted in two phases (November 2018 to January 2019 and January 2021). The respondent sample was selected by a proportional representation of industrial SMEs in the given regions and iron and mining industries with data provided by the Czech Statistical Office, and finally, 240 SMEs were investigated for the research purpose. The research shows that awareness of the digitization of the economy in SMEs in the Czech Republic (Industry I-5.0 initiative) is not the highest. The transition to a digital economy in these enterprises has been slow. Sufficient tools have not been developed in time to support their manufacturing and economic activities, to implement and safeguard the digitization of their production, nor have any real measures been created to enforce Industry 5.0 priorities, including digital administration. This research also formulates key recommendations for executive bodies in the Czech Republic. All this is in order to establish interventions in the sector of industrial SMEs so that digitization processes and standards in this sector might be strengthened.
\end{abstract}

\section{Keywords}

Digital society, digital economy, SMEs, digitization of industry, industry 4.0 and 5.0, modernization of production and control systems, smart industrial production, digital innovation, iron and mining industries. 


\section{Introduction}

The global economy is undergoing significant changes. Predicting the behaviour of changes, visions, and ways to achieve them must not overlook certain handicaps that accompany the advanced industrial economies of the EU and a number of countries associated in the OECD. According to some authors (Lupan \& Carmen, 2006), these are long-term disparities between low and high-income groups, according to others (Afontsev, 2019; Liu \& Warwick, 2019) unfavourable demographic growth and high social standards. As the latter point out, it is always easy to set a vision (for example, safeguard sustainable and "green" global industrial growth), but it is much more difficult to identify appropriate ways to achieve it in a challenging and competitive environment. There is no doubt that structural changes will continue in this direction, not only between sectors of the economy but also within individual sectors. Innovation is generally considered to be a key attribute for increasing the competitiveness of the industrial economy (Ermolaev et al., 2019). It is a broad concept that encompasses the development and preparation of new products as well as the application of new materials and new technologies. By its nature, innovation can undoubtedly include activities related to the digitization of the economy. This particular case is more than just the individual direction of innovation, rather a complex of digital activities which, if interconnected, offer a synergistic effect in a new quality. This quality can be reflected in both products and their production (and in entire production systems), but it also overlaps with distribution systems (the entire value chain). In addition, these practices affect more than just industry (where a number of partial and successful applications can already be found), suggesting that they will affect all of society in the near future (Dobrinskaya, 2021). The term digital society is therefore used in this context.

The first indications and mentions of the digital society in the importance of national economies and entities begin to appear at the end of the last century. The OECD "Digital economy outlook 2015" (OECD Digital Economy Outlook, 2015) states that current national digital strategies affect both industry and public administration, health care, the environment, etc. Governments recognize the need to pay special attention to digital policy and, in this context, infrastructure development. At the same time, cyber security, including privacy, must be strengthened. The article below also draws attention to the impact of digital strategies on people who need to be given the appropriate ICT skills and knowledge to manage risks. Unfavourable demographic developments in the industrialized countries of the OECD should continue as a negative trend in the coming years. According to Marin (2018), other effects besides the problem of social stability are certainly expected in a smaller workforce, increasing difficulty adapting an ageing workforce to new professions, and of course, there will be changes in the structure of demand for industrial workers.

Other impacts of the digitization of society can also be expected (Katzenbach \& Bachle, 2019). Growing wages in less developed economies and a rising tide of instability will lead to a reassessment of offshoring (relocating cooperative production to less developed countries) while these markets will continue to serve as reshoring markets. It will be vital, however, to grasp the changing trends of these less developed countries: migration from villages to cities and the emergence of a middle class (especially in Asia) from the current 1.8 billion to 3.2 (in 2020) and 4.9 (in 2030) (OECD Digital Economy Outlook, 2015). The growing revenue in emerging economies is generally expected to positively impact demand in these countries.

Developed industrial countries should respond to the above trends through advanced production technologies using automation, information coordination, software, sensor deployment, and network connections of 3D printers (not only to produce models or prototypes but also their own components for production), as well as through making new products based on new materials (nanotechnology, biotechnology) (Levin \& Mamlok, 2021). Future competitiveness will depend on the successful combination of design, new materials, research and modern production systems. OECD Secretariat (Directorate of Science, Technology and Innovation) (2015) states that IoT, the Internet of Things, 3D printing, and industrial biotechnology and nanotechnology have the potential to change production prospects dramatically over the next 10-15 years, supporting a new industrial revolution and the key to it all will be in industrial production. This revolution will have an impact on the labour market and new skills. Current regulations used in managing the economy will have to change. Not to be overlooked is the fact that the share of OECD countries in world manufacturing production fell from $85 \%$ (in 1970) to 55\% in 2013, while Chinese manufacturing production in that same year was $25 \%$ (Xu et al., 2021). The globalization model of the division of labour has been aimed at taking the production and assembly of parts or entire products, as well as a range of services, especially those that are labour-intensive, to countries with lower costs. The manufacturing industry is a key producer of added value, it makes up the majority of investments, and it is a major player in foreign trade.

It is obvious that the modernization of the industrial production base caused by the digitization of industry (Jieping et al., 2011) will impose a change in the production park and introduce machines and robots interconnected in cyberspace, which of course cannot happen without demands being placed on energy resources. All these transformational changes affecting production and management systems should respect the energy policy's intentions, especially aimed at increasing energy efficiency. 
This current article focuses on the aspects of the digitization of industry in the sectors of iron and mining, respectively the readiness of these businesses for new trends associated with digitization and Industry 5.0. This is partly because they face a number of obstacles that need to be addressed. One of them (apart from the lack of funds for the digitization process itself) is the absence of experts (Sochul'akova \& Kral'ova, 2020) who could fully devote themselves to the methodologies of introducing I-5.0 in SMEs. Their lukewarm attitude towards Industry 5.0 is also supported by concerns about information security and data protection. An extensive study by the German Chamber of Commerce and Industry indicates that only $27 \%$ of SMEs consider themselves to be fully or almost entirely up-to-date digital-wise (Sommer, 2015).

Also, the degree of the virtualization of processes strongly depends on the type of industry and the size of the company. SMEs often cannot afford independent resources for simulation and modelling purposes (Verhovnik \& Stojmenova, 2021). In order to overcome the barriers associated with the integration of the virtual processes of industrial SMEs into the real mass production of their own businesses, it is important to have educational and research facilities address the issue. The reasons for academic transfer may pose two main research questions. How do SMEs perceive the benefits of digitization processes? How do the management and employees of SMEs perceive barriers to the transition to Industry 5.0, and what processes affect their use and adoption of new methods and tools?

Because this paper focuses on a comprehensive approach to the issue, it differs from other studies. In addition, the companies analyzed by the article have mostly never applied a general model of corporate digital readiness. For these reasons, this study may arouse the interest of practical experts, policymakers, entrepreneurs and academics in the results of this research. This is because the results will inform all market players about whether or not it is beneficial to implement digitization processes for a specific SME.

The rest of the paper is structured as follows: Part 2, "Material and Methods", not only details the main points of the research into the sector by conducting an extensive review of the literature and by providing important information from other related studies but also explains the data and methods used in this article. Part 3 highlights the results of this document. Part 4 discusses the main results and provides potential reasons for the findings by addressing the problems faced by SMEs in the digitization process. Finally, in the Conclusions, the work concludes the main results with a summarization of other important facts about this research.

\section{Material}

\section{Material and Methods}

The introduction of elements of the digital economy in industrial SMEs clearly increases their potential competitiveness and thus creates a way to increase the productivity of their production. This has been doubly true (Sharifi et al., 2021), with society facing the challenges and impacts of the Covid-19 pandemic. These threats have accelerated digital transformation processes in industrial enterprises (Javaid et al., 2020).

The European Commission is also working on digitizing industrial enterprises (Svarc et al., 2021; Digital Agenda EU, 2020). In order to strengthen the European digitization of companies, measures with clear European added value are being proposed:

- Joint investment in digital innovation. In this context, it is recommended to support the building of centres for digital innovation (including private-academic links) public-private partnerships to achieve leadership in the value chain (from components to applications) and platforms; the standardization of information and communication technologies cannot become the focus,

- Ensure appropriate regulatory conditions (limit barriers to the free flow of data in the EU, data ownership, security, accountability of autonomous systems and the Internet of Things, etc.),

- Human capital for digital transformation (dialogue with social partners, new digital skills).

The modernization of the production base caused by the digitization of industry ("vertical integration") will clearly evoke change in the production park and introduce machines and robots interconnected in cyberspace. All these transformational changes, which affect production and management systems, should respect the abovementioned conclusions of the EU energy policy, in particular with a view to increasing energy efficiency. European Commission (2016) notes in the document of "Digitizing European Industry Reaping the full benefits of a Digital Single Market" that various initiatives are also taking place at the national level, for example, Industrie 4.0 and 5.0 (Germany), Smart Industry (Netherlands), Catapults (United Kingdom) and Industrie du Futur ( France).

The Industry 4.0 and 5.0 platforms are tools for supporting digital structural changes, for discussions by businesses, academia, unions and politicians, and for presenting recommendations and examples for a successful transition to the next generation of the industry. The rapid pace of technological progress in Industry 4.0 and Industry 5.0 is making organizational competition increasingly intense in all sectors and industries. Technological competitiveness is considered a key element in differentiating organizations from the competition, in anticipating new markets, generating competitive advantages, and improving organizational performance and sustainability (Acur et al., 2010; Özdemir \& Hekim, 2018). Digital innovation platforms are developing a new type of production environment. Smart machines, storage and logistics systems and other production facilities are united into one 
unit, where the individual elements of the production process are capable of autonomous intercommunication, information exchange and mutual self-control. The production environment in the form of a cyber-physical system brings with it a radical improvement in all production processes, from design, production, and the logistics of chain management to continuous customer support and preventive maintenance throughout the life cycle of the product (Javaid et al., 2020).

"Smart factories" built as cyber-physical systems offer an innovative approach to production and are a key element in the transition to fifth-generation industries (Okeme et al., 2021). Smart factories are able to manage the complexity of the production process autonomously and with high efficiency and added value. In smart factories, people, machines, and resources naturally communicate with each other analogously to communication in today's digital social networks. The smart factory is connected via digital interfaces to smart mobile devices (which are the main interface to human users), smart power grids, smart logistics and other supporting elements (Shi et al., 2020; Sufian et al., 2019). Thus, it becomes the focal point of tomorrow's "smart" infrastructure of everyday life. We can talk here about the Internet of Everything and the extensive digital transformation - these will have an impact not only on changing conventional value chains and on generating new business models, but also on everyday life, on high culture and on human institutions.

The digital transformation of industrial enterprises into the form of 5.0 will occur (Özdemir \& Hekim, 2018) at three basic levels. The first is the integration of the production environment and the replacement of old equipment with new gear adapted to digital integration (existing production systems consist of unrelated units). Newly implemented elements of the integrated production environment will respect the standards of its reference architecture and thus be easily integrated with each other. A process transformation then follows. Existing production environments are primarily based on highly inflexible closed software systems. Thanks to these systems, digitized processes are linear and static, and the agility needed often means that complex processes are not digitized at all. These systems are fragmented and often linger well below their potential performance in terms of digital continuity. Digital transformation will make new processes agile and open and will cover the entire digitized production environment. This agility has proved very useful as a tool for production changes during the COVID -19 period (Javaid \& Haleem, 2020), and it is followed by educational and social transformation (Nahavandi, 2019). This approach can also be understood as an indirect reaction to the demographic changes associated with the ageing population of developed industrial countries, not excluding the Czech labour market. The goal is to maintain or increase the current standard of living, primarily by increasing the qualifications and productivity of current employees, including an ever-dwindling number of new employees entering the production process.

The segment of industrial SMEs in advanced economies represents an important component of the economy (Belas et al., 2020). As an undoubtedly important employer, it is the leading absorber of the unemployed in times of stagnation or crisis. It is an element that is expected to be dynamic and flexible in response to various changes in socio-economic development. SMEs are significant players in economies since they reduce poverty by creating job opportunities (Amoah et al., 2021; Civelek et al., 2020).

Good examples of the implementation of digital technologies in industrial production (Belov, 2016) are presented by renowned German companies and pilot projects in research clusters. Representatives of these companies work together with research institutions, and with the support of the Ministry of Economic Cooperation, they actively implement and create a digitized world of work. The way the German public sees it, however, there are only a few industrial SMEs outside the influence of ministerial subsidies that present their work as the knowledge and processes of industrial digitization (Greef \& Schroeder, 2021). In the perception of German industrial SMEs, the term Industrie 5.0 is understood primarily as Digital Networked Systems (54\%), Intelligent and Flexible Manufacturing Processes (50\%), General Digitisation of Everything (48\%) and Smart Factory (48\%). We do not have detailed data on the situation in Switzerland, as the project of systemic digitization of industrial SMEs involves mainly large companies. But according to Robert Rudolf (the founder of the Swiss initiative "Industrie 2025"), these companies in Switzerland are ready for change and are already implementing it internally (Sanders et al., 2019). Meanwhile, initiatives for systemic support for the digitization of (Industry 5.0) industrial SMEs in the Czech Republic do not exist (Mladek, 2017). One of the few activities is a model developed to show the digital maturity of industrial SMEs (Evaluation form, 2021, available only in the Czech language). The causes and effects of this fact will be addressed in the next part of the article. For now, certain barriers identified in the materials (Simanova \& Kocourek, 2019) were confirmed in the following survey.

\section{Methods}

The aim of this research is to clarify the current situation in the readiness of Czech SMEs for new trends associated with digitization (especially the Industry 5.0 initiative). The research into this readiness was carried out using a questionnaire survey and semi-structured interviews. The survey sought to clarify the implications of the implementation of industrial enterprise digitization processes (I-5.0) to identify the benefits, support, risks, and barriers to implementing this initiative and vision. 
The questionnaire survey is based on the stated objectives, and it contributes to the verification of the formulated hypotheses. The hypotheses were determined in accordance with the conclusions of the author's previous studies (Pomffyová et al., 2018; Krajčík, 2018; Krajčík et al., 2018; Cienciala et al., 2013). The null hypotheses are set so that less than $50 \%$ of the total number of respondents agree with the statements in hypotheses $\mathrm{H} 1$ and $\mathrm{H} 2$.

H1: Awareness of the digital industry 5.0 (I-5.0) is still very low in the industrial business sphere of the industrial SMEs.

$\mathrm{H} 2$ : There are differences in the perception of the risk of impacts of I-5.0 on industrial enterprises operating in the Czech Republic

H3: Investments in I-5.0 technical, communication and software solutions are highly expensive, and a large part of SMEs in the sector will not be able to afford to implement them from their own financial resources.

H4: The SMEs segment lags behind large companies in I-5.0 innovation activities.

The first phase focused on the preparation of the questionnaire and its pilot verification (sample of 16 respondents). It was conducted in January-April 2018 and is based on the evaluation of data from the Czech Statistical Office. According to data from the category Numbers and Size of Enterprises in Industry (CZ-NACE, $\mathrm{BE}$ ), a proportional representation of $11.4 \%$ (number of employees 1-9), $20.6 \%$ (number of employees 10-49), and $30.5 \%$ (number of employees 50-249) were chosen. The piloting took place in the Moravian-Silesian Region with the use of methodological support from students of the University College of Business and the University of Business and Law. The piloting of the first version of the questionnaire led to formal adjustments and partial changes in the wording of the questions. The second phase focused on data collection. It took place in two phases (November 2018 to January 2019 and January 2021). The respondent sample was selected from a proportional representation of industrial SMEs in the regions using background data from the Czech Statistical Office. The core database shows there were a total of 12,054 enterprises in the Czech Republic and 38,088 industrial enterprises when micro-enterprises were included. Of the fourteen regions of the Czech Republic, more than ten per cent of industrial enterprises are in Prague (15\%), the South Moravian Region (12.8\%) and the Moravian-Silesian Region (10.1\%). The Karlovy Vary Region (2.4\%), the Liberec Region (4.5\%) and the Vysočina Region (4.8\%) have the smallest share in the number of industrial enterprises in the Czech Republic. Using these percentages, industrial SMEs were contacted by random selection. On account of the H1 hypothesis, foreign capital ownership was also included in the selection criteria. Data from both the Czech National Bank and Česká kapitálová společnost (ČEKIA) in 2014, approximated for 2016, was used to determine the share of Czech foreign corporate owners. It showed a proportion of $50 \%$ (domestic owner) to $42 \%$ (foreign owner). The remaining percentages were not taken into account (tax havens, unknown owner, etc.).

The questionnaire was distributed as a form in the environment of Microsoft Forms (Office 365 Education) using a direct email address acquired from the database of the Czech Chamber of Commerce. The form was accompanied by a letter explaining and describing the aim of the research. The third phase was focused on statistical evaluation, interpreting the individual parts, and the formulation of conclusions. Statistical analysis was performed in IBM SPSS Statistics. The structure of the questionnaire was based on the assignment and consisted of 3 blocks of questions: a brief description of the Industry I-5.0 initiative, identification questions and factual questions. These focused on the following areas: awareness of Industry I-5.0, the relationship of the organization in question to the digital economy, awareness of the digital maturity model of the company, and the innovative activities of the organization.

Similar to the structure of the questionnaire, the respondent sample was based on the entire research task. A total of 240 questionnaires (a return of 15\%) were processed in the following respondent structure:

Tab. 1. Sample profile

\begin{tabular}{llcc}
\hline & & $\mathrm{n}$ & Share \\
\hline Firm size & Micro & 60 & $25 \%$ \\
& Small\& medium & 180 & $75 \%$ \\
\hline Gender & Male & 140 & $58.3 \%$ \\
& Female & 100 & $41.7 \%$ \\
\hline Agerk experience & Up to 10 years & 150 & $62.5 \%$ \\
& More than 10 years & 90 & $37.5 \%$ \\
\hline Education & Up to 40 years old & 110 & $45.84 \%$ \\
& More than 40 & 130 & $54.16 \%$ \\
\hline \multicolumn{2}{c}{ Source: Own processing. } \\
\hline & Less than bachelors' & 90 & $37.5 \%$ \\
& Bachelors and more & 150 & $62.5 \%$ \\
\hline & Total & 240 & $100 \%$ \\
\hline
\end{tabular}


A total of 13 companies were selected for the semi-structured interviews, of which only 12 companies were evaluated. The sample was selected on the basis of documents from the Czech Statistical Office according to the expenditures of individual SMEs on product innovations. These represent the launch of a new or substantially improved product whose characteristics or intended use differ significantly from the company's previous products. At the same time, this indicator was weighted by the criterion of ICT expenditures in these companies and success in the subsidized resources of ICT programs and strategic services, or ICT in companies. According to their core business as industrial SMEs, the companies were located in Prague (25\%), the South Moravian Region (25\%) and the Moravian-Silesian Region (50\%). The individual companies that agreed to the publication include MEZSERVIS spol. s r. o.; ASY s.r.o.; TECONT s.r.o.; ESY s.r.o.; Ingeteam a.s.; ATACO spol.s r.o.; Steel Servis Centrum; and TERMONTA PRAHA, s.r.o. The actual survey was conducted in January 2021. The choice of the "face-to-face" survey method was prompted by the assumption that part of the professional public had heard about the issue of I-5.0 (not always under this formulation). Not everyone understands it in exactly the same way. This assumption was confirmed during the semi-structured interviews. At the beginning of the interview, it was first necessary to clarify what the representatives of industrial SMEs represent according to the above terms and how they perceive them. The interview itself was conducted by trained interviewers from among university students, and the interview was recorded and subsequently evaluated.

A checklist was prepared for the interview, which served as a guide for the interviewers and contained a number of topics for conducting the interview: identification of the organization, awareness of the I-5.0 initiative, the resources (preconditions) of the organization for implementing I-5.0, modernization of production and control systems (vertical integration), digitization of supply and demand chains (horizontal integration), identification of customers and their relationship to smart production.

\section{Results}

The questionnaire survey was divided into factual, closed and open-ended questions. The aim of the factual questions was to identify the distribution of respondents according to region, the main distribution of their activities, the ownership proportion of the analyzed entities, the link to foreign entities and the identification of the method of communication between the analyzed entities and business partners. The analysis of the closed questions made it possible to examine the closer affinity of industrial SMEs in the Czech Republic for the digitization of processes and the Industry 5.0 initiative. Specifically to assess awareness of Industry I-5.0. Only 13.7\% of respondents said that their company management has already made strategic decisions on the implementation of I-5.0 principles and taken steps to ensure their implementation. Likewise, 5.9\% said that their management only made a strategic decision on the implementation of Industry I-5.0.

Furthermore, $8 \%$ of the surveyed business with representatives of the organization are acquainted with the requirements of the Industry I-5.0 initiative (participation in conferences, study of materials, etc.). The vast majority then reported that awareness of the Industry I-5.0 initiative is slim or non-existent. Other questions focused on the relationship of employees to the digitization of business processes and the relationship to Industry 5.0. Here we find that the attitude of the addressed companies to the Industry I-5.0 initiative is quite conservative. The nice thing is that organizations would welcome more information about this initiative, which suggests that they are interested in the prospects of this concept. This is illustrated by their specific answers.

A total of $13 \%$ of the respondents say that they owe their awareness and first implementation to their own initiative and that $18 \%$ are still in the process of discovering knowledge and experience about these initiatives. Furthermore, $25 \%$ would welcome more information about the content, meaning and demands of these activities. Particularly alarming is the fact that $39.5 \%$ say that they have no involvement in the above activities that they have other priorities. Important are the answers to the issue of their company's digitization maturity model. Almost $60 \%$ of respondents, employees of industrial SMEs, have never encountered the model, and $32 \%$ do not support the introduction or verification of the model in a particular enterprise. Thus, hypotheses $\mathrm{H} 1$ and $\mathrm{H} 2$ have been confirmed (see Table 2). Awareness of I-5.0 is still very low in the industrial business sphere of the SME sector, even in the case of companies with foreign participation. 
Table 2: Table of the significance of the test hypotheses $H 1$ and $H 2\left(\chi^{2}\right.$ test $)$

\begin{tabular}{|c|c|c|c|}
\hline \multicolumn{4}{|c|}{ Knowledge and awareness of the I-5.0 initiative in numbers (n) of respondents - values of absolute frequency } \\
\hline & relevant low & relevant high & total \\
\hline $\begin{array}{c}\text { number of enterprises with } \\
\text { foreign participation }\end{array}$ & 102 & 38 & 140 \\
\hline $\begin{array}{l}\text { number of enterprises without } \\
\text { foreign participation }\end{array}$ & 84 & 16 & 100 \\
\hline total & 186 & 54 & 240 \\
\hline \multicolumn{4}{|c|}{ Contingency table of expected frequencies } \\
\hline $\begin{array}{c}\text { number of enterprises with } \\
\text { foreign participation }\end{array}$ & 108.5 & 31.5 & \\
\hline $\begin{array}{l}\text { number of enterprises without } \\
\text { foreign participation }\end{array}$ & 77.5 & 22.5 & \\
\hline P value & & 0.042 & \\
\hline
\end{tabular}

Other questions examined the problems of digitization in the organization and the differences in how the risk of I-5.0 for industrial enterprises has been perceived. A total of $12.2 \%$ gave two or more answers, of which the most common indicated that there was no problem, that it was in progress, or it was not topical for the organization. Digitization in the observed organizations is either not a problem or satisfactory (almost $84 \%$ in total). The question is how companies understand the process of digitization, given that organizations with up to 10 employees (cumulatively) represent $62.9 \%$ of the research group. Of the total sample, $15 \%$ encounter a lack of funds, while $13 \%$ cite the insufficient digital literacy of their employees as a factor. However, no significant differences were noted in the answers regarding the structure of employees and the location of companies within the Czech Republic. In the last series of closed questions, the innovative activities of companies were evaluated in relation to digitization processes.

A total of 76 respondents $(32.2 \%)$ gave two or more answers, most often: they respond to the demands of customers or suppliers and act according to current needs ( $8 \%$ of respondents), or they manage digital innovations in a planned manner and respond to customer and/or supplier requirements (7\% of respondents). There was significant agreement (87\%) that investments in technical, communication and software solutions are highly expensive and that a major portion of SMEs in the sector will not be able to afford to implement them from their own financial resources on an ongoing basis.

One of the explanations is that the questionnaire confirmed that $42 \%$ of the answers state that innovations or various improvements in products or services occur according to current needs. Particularly surprising is the statement of $16 \%$ of answers that they do not pay much attention to product innovation because they are producers of traditional products. In line with these results, H3 is confirmed.

The final round of questions was open-ended and so made it possible for the respondents to formulate their own views on digitization processes. The individual answers were grouped into the same or similar content groups. The formulation was to cite any threat the respondent felt to their core business in the future (multiple variants could be selected). According to the groups, $13 \%$ of threats were identified in association with the legislative framework ("In the stability of Czech legislation", "New legislation, again regulating and punishing legal employment agencies and their customers while the illegal labour market is booming", "Complex, uncertain and constantly chaotic changes in the legal framework for doing business"). Furthermore, $42 \%$ have concerns about the competition ("Possibility that our company will not be selected in the tender", "Competition from large players who offer, for example, cloud services much cheaper than we can provide them"). Other threats were also mentioned ("Closing the Czech branch due to the lack of experts necessary for growth", "All variants are a risk in the SWOT analysis", "Seasonality").

The controlled interviews with representatives of industrial SMEs were evaluated according to the above method. The conclusions from the survey can be summarized in the following points:

- The level of awareness of the digitization of industry I-05 is at various levels; companies obtain it on their own initiative, from conferences and trade fairs, professional periodicals, the Internet, etc.,

- None of the companies surveyed adopted a strategic plan or programme for I-5.0; none of the companies surveyed had a customer that required radical changes in horizontal communication, nor did it require that the products it supplied be innovated in the direction of smart products. For this reason, no decision was issued to their development departments; the interviewed companies see some space in the further implementation of automation in their production systems, however, without their involvement in integrated production and control systems or in cyberspace; 
- Most of the surveyed companies are not ready to do business in the spirit of I-5.0 requirements; the main problem of the surveyed companies is the lack of qualified people in general for their growth, which also applies to the lack of sufficiently qualified staff for I-5.0 activities,

- Another important problem is the lack of funds, with our medium and large companies feeling at a disadvantage to giants such as ABB, SIEMENS, GE, Foxconn, etc.

Using a formal analysis of the interviews (in the case of innovation activities in relation to businesses), several interesting conclusions can be drawn:

- On the positive side, overall spending on I-5.0 product and process innovation is increasing over time,

- The structure of these expenditures shows that half (investments) are for the acquisition of machinery, equipment, or software; the in-house information system is in the second place, and the purchase of science and research services is in the third,

- More foreign-controlled enterprises than domestic ones can be considered "innovative", as well as large enterprises followed by medium and then small ones.

All the above facts confirm hypothesis H4: The segment of industrial SMEs in the Czech Republic lags behind large companies, especially those with foreign ownership, in innovation activities leading to I-5.0.

\section{Discussion}

The digitization of industry and processes defined by the Industry 5.0 platform is a tool to support digital structural changes, to generate discussion among businesses and academia, unions and politicians, to present recommendations and examples for the successful transition to the fifth generation of industry (Alvarez-Aros et al., 2021). Although there have been some practical experience (Siemens Amberg), the Industry 5.0 initiative as a whole is still on the research agenda with several experimental applications. Especially in the sector of industrial SMEs.

However, it is impossible to overlook some critical opinions (Javaid \& Haleem, 2020) on Industry I-5.0 that have been appearing in professional circles. On the one hand, the connection with the state and the resulting cumbersomeness in comparison with, for example, the USA, has been criticized, and on the other is the certain illusion of the whole concept, based as it is on the needs of research and large companies supplying old products in new packaging, financed mainly by taxpayers (Salimova et al., 2020).

The example of Lin et al. (2017) is instructive. In this paper, the authors describe two years of work on a standard in one of the working groups of I-4.0 and I-5.0. Due to legislative restrictions, he was unable to publish the elaborated standard and work on it further - that would be a violation of the competitive environment. Other participants described how Germany lagged behind the US in the same forum.

Other papers criticize the contrast between large suppliers and SMEs (Javaid \& Haleem, 2020) and the mutual incompatibility of the data of delivered products for manufacturing infrastructures (John et al., 2020). The very term "Industry 5.0" has also been criticized (Xu et al., 2021). According to the authors of the study, it is interesting that "for the first time in history, a technical industrial revolution was announced before it took place". Javaid and Haleem (2020) indicate microelectronics as the basis of ongoing processes and argues that this base has remained essentially unchanged, and therefore we cannot speak of revolutionary change, but only "the next phase of digitization".

According to Salimova et al. (2021), it is indeed possible to speak of a revolution. However, it does not consist only of the digitization of existing industrial technologies, i.e. in the implementation of a "smart factory" on the floor plan of existing organizational processes, but in the digital transformation of our entire economic and social environment (Society 5.0), a new method of production using cybernetic models and new technical resources that can include, for example, cooperative robots. The I-5.0 approach is a real revolution (John, 2020), as it turns the understanding of production and service, both digital and physical, upside down.

A certain problem that needs to be addressed in the near future is the cautious or reserved approach of the SME segment towards Industry 5.0. This is due to the fact that the current positive examples and experience with the application of usually only partial solutions of Industry 5.0 come from large companies and are usually not accompanied by arguments about their economic efficiency. In addition, these companies have concerns about the security of information systems and the risk of data leakage.

However, a much more radical critique is contained in Syska and Lievre (2016) study, which speaks of Industrie 4.0 and subsequently I-5.0 as Germany's naive dream of a smart factory. After it was released in mid2016, the publication found a number of supporters and, of course, opponents. Proponents of Illusion 4.0 do not reject the concept of Industry 5.0 but point out that the Industry 5.0 initiative is communicated only positively and with the strong support of executives and politicians. At the same time, there is a lack of dialogue focused on future scenarios of this development. The identification with Syska and Lievre (2016) prevails mainly in the focus of the initiative, where solutions that bring efficiency and productivity to production systems are especially favoured (Di Nardo \& Yu, 2021). The focus on the added value created by new business models seems to be 
secondary. Early practitioners agree that the book is critical but not destructive. To all who are not indifferent to the fate of industry or business, he suggests that Etiquette 5.0 may have "something" different in its content that they should be interested in. The book can be seen as a constructively critical guide on how to prevent the illusion and therefore exaggerated expectations from the previously presented direction of Industry 5.0. It is also possible to agree with the opinion that Industry 5.0, as an initiative for the development of industry (especially SMEs), is celebrating the second anniversary of its existence. This concerns the large companies that supply technology to industrial SMEs and research organizations that benefit from this initiative.

Following the discussion with the representatives of industrial SMEs, the following risks to the introduction and implementation of I-5.0 can be expected from the point of view of systemic national measures for Czech companies. The government has not found a way to prevent the shortage of skilled labour in industry and likewise specialists for I-5.0 at all levels, and so there has been an outflow of capital, including foreign investment. There is a complete lack of students and doctoral candidates for hire by I-5.0 researchers and implementers. The transition to a digital economy in industrial SMEs has been slow. Sufficient tools have not been developed in time to support production and economic activities, to safeguard cyber security, nor to have real measures created to enforce I-5.0 priorities, including digital administration. The widespread deployment of high-speed internet and shared services has been slow, and there is insufficient awareness. Much of human interaction is shifting to digital space, creating vast amounts of digital data whose algorithmic analysis promises new knowledge and access to new opportunities, but at the same time, it creates many risks in the labour market that we cannot adequately describe. This creates room for negative views on I-5.0. The government has not found the appropriate motivational tool to support I5.0, nor a tool to conduct qualitative and quantitative evaluations, not only of digital efficiency but also of innovation and research activities in the field of I-5.0. There is a reluctance on the part of academia to share responsibility for industrial development. The statistical system and accounting, including tax administration data, are not flexible enough to monitor new innovations their effectiveness or to provide feedback for the creation of new tools to support I-5.0. There is a general lack of understanding of the necessary interdisciplinarity of I-5.0, not only in the labour market but also in science and industrial research. The traditional view of manufacturing industries, crafts, the division between technical fields and humanities have not been sufficiently described and perceived in connection to cyber-physical systems,

In particular, new economic industrial models and research support for new "smart" products and cyber security in the industry are lacking. The government does not sufficiently motivate the involvement of employees of industrial SMEs in the creation of new standards or norms. Indeed, the availability of standards has deteriorated, which has resulted in the poorer readiness of products for certification. The dissemination of standards has been tied to a new way of distribution, with licensing conditions that are very costly for SMEs. Intellectual property protection is difficult for them not only for financial reasons but mainly because SMEs have not mastered sufficient professional skills in this area, nor do they know the appropriate procedures to use intellectual property protection to support their innovative activities.

\section{Conclusions}

This study contains a wide range of data, as well as evaluations, intended to provide much up-to-date information on developments in the last decade in SMEs that operate in iron and mining industries of the Czech Republic, but also in selected countries in connection with trends in the digitization of advanced economies. The following text summarizes the previously mentioned partial conclusions or puts them into context.

Awareness of economic digitization in SMEs in the Czech Republic (initiative I-5.0) is not the highest. They gain knowledge of it by attending conferences, through the self-study of articles on the Internet, etc. More than a quarter of respondents would welcome more information about the content and meaning of these initiatives. In most organizations in this group, no strategic decisions have been taken towards digitization or I-5.0, but a number of organizations (14\%) are implementing the first partial steps. The interest of SMEs in the digital economy or I5.0 owes to their own initiative or, to a smaller extent, the initiative of their parent company, customers or suppliers. The surprising conclusion of the survey is that about $40 \%$ of respondents do not intend to address this issue in the near future because they have other priorities. Digitization and I-5.0 processes are not perceived by the respondents as an immediate risk to their future development. For them, the problem is a lack of qualified staff, lack of orders, maintaining competitiveness in innovation, quality, and prices. The introduction of digitization, i.e. I-5.0, is closely related to the innovation culture established in the company, and in this light, the statements of the respondents about innovation activities are not very optimistic.

Based on the analysis of primary or secondary data and the results of direct surveys, the following recommendations can be formulated for executive bodies in the Czech Republic. All this is meant to define interventions in industrial SMEs in order to strengthen the digitization processes in this sector. This is mainly the focus of EU operational programmes for the current programming period when operational programmes represent an important source of public funds intended to support industrial SMEs. Interventions can be recommended in areas such as cyber security, data protection, in particular privacy, the facilitation of digital interactions, and in the 
interoperability and portability of data. Related to this are shifts in the content of teaching in the school system, as well as in non-formal education (retraining, lifelong learning focused on I-5.0).

By focusing on the views of SMEs on the benefits, support, incentives, risks, the security issues of digitization and the I-5.0 initiative, this article makes a significant contribution to related academic literature. However, this study has some limitations, especially regarding its sample size. In addition, it only analyses industrial SMEs that operate in a limited space, such as the iron and mining industries. It also does not take into account any characteristics of companies or executives in order to compare them. In this regard, other studies may include more companies in their samples and so consider the perceptions and contexts of I-5.0 by some larger firms as well. Researchers can also analyze companies from different countries with different characteristics.

\section{References}

Acur, N., Kandemir, D., De Weerd-Nederhof, P. C., \& Song, M. (2010). Exploring the impact of technological competence development on speed and NPD program performance. Journal of product innovation management, 27(6), 915-929. https://doi.org/10.1111/j.1540-5885.2010.00760.x

Afontsev, S. (2019). New trends in Global economy. Mirovaia ekonomika i mezhdunarodnye otnosheniia, 63(5), 36-46. https://doi.org/10.20542/0131-2227-2019-63-5-36-46.

Alvarez-Aros, E. L., \& Bernal-Torres, C. A. (2021). Technological competitiveness and emerging technologies in industry 4.0 and industry 5.0. Anais da Academia Brasileira de Ciências, 93(1) https://doi.org/10.1590/0001-3765202120191290.

Amoah, J., Jibril, A.B., Luki, B.N., Odei, M.A. \&Yawson, C.(2021). Barriers of SMEs' sustainability in subsaharan Africa: a pls-sem approach. International Journal of Entrepreneurial Knowledge, 9(1), 10-24. https://doi.org/10.37335/ijek.v9i1.129

Bednárik, J. (2018, October). Circular economy as a prerequisite of sustainable development in the global environment. In Proceedings of the 18th International Scientific Conference on Globalization and its SocioEconomic Consequences (pp. 986-993).

Belas, J., Amoah, J., Petráková, Z., Kliuchnikava, Y., \& Bilan, Y. (2020). Selected factors of SMEs management in the service sector. Journal of Tourism and Services, 21(11), 129-146. https://doi.org/10.29036/jots.v11i21.215

Belov, V. B. (2016). New paradigm of industrial development of Germany-Strategy “industry 4.0”. Современная Европа, (5), 11-22. https://doi.org/10.15211/soveurope520164146.

Chen, C. Y. H., \& Härdle, W. K. (2017). Data science and digital society. In Proceedings of the International Conference on Business Excellence 11(1), 669-675. https://doi.org/10.1515/picbe-2017-0071.

Cienciala, J., Krajčík, V., \& Tacina, M. (2013). Improving of processes in the metallurgical company focusing on information and human resources processes", pp. 1638-43 in METAL 2013: 22nd International Conference On Metallurgy And Materials.

Civelek, M., Gajdka, K., Světlík, J., \& Vavrečka, V. (2020). Differences in the usage of online marketing and social media tools: evidence from Czech, Slovakian and Hungarian SMEs. Equilibrium. Quarterly Journal of Economics and Economic Policy, 15(3), 537-563. https://doi.org/10.24136/eq.2020.024

Di Nardo, M., \& Yu, H. (2021). Special Issue "Industry 5.0: The Prelude to the Sixth Industrial Revolution". Applied System Innovation 4(3). https://doi.org/10.3390/asi4030045.

Dobrinskaya, D. E. (2021). What is the Digital Society? Sociologia Nauki I Tehnologij-Sociology Of Science \& Technology 12(2):112-29. https://doi.org/10.24412/2079-0910-2021-2-112-129.

Ermolaev, K., Matveev, Y., Trubetskaya, O., \& Gromova, T. (2019). Institutional changes and digital economy. Global Challenges and Prospects of the Modern Economic Development. European Proceedings of Social and Behavioural Sciences, 57, 580-589.

European Commission (2016). Digitising European Industry Reaping the full benefits of a Digital Single Market, Brussels 2016, Retrieved from: https://eur-lex.europa.eu/legalcontent/EN/TXT/PDF/?uri=CELEX:52016DC0180\&from=en

Evaluation form (2021). Retrieved from: http://firma4.cz/hodnoceni-digitalni-zralosti-firmy/, in Czech

Gorodetsky, V., Larukchin, V., \& Skobelev, P. (2019, October). Conceptual model of digital platform for enterprises of industry 5.0. In International Symposium on Intelligent and Distributed Computing (pp. 3540). Springer, Cham.

Greef, S., \& Schroeder, W. (2021). How does Industry 4.0 affect the relationship between centre and periphery? The case of manufacturing industry in Germany. European Planning Studies, 29(9), 1656-1671. https://doi.org/10.1080/09654313.2021.1963051.

Javaid, M., Haleem, A., Singh, R. P., Haq, M. I. U., Raina, A., \& Suman, R. (2020). Industry 5.0: Potential applications in COVID-19. Journal of Industrial Integration and Management, 5(04), 507-530. https://doi.org/10.1142/S2424862220500141. 
Javaid, M., \& Haleem, A. (2020). Critical components of Industry 5.0 towards a successful adoption in the field of manufacturing. Journal of Industrial Integration and Management, 5(03), 327-348. https://doi.org/10.1142/S2424862220500141

Jieping, H., Rijie, C., \& Yaqiong, W. (2011, September). The research and progress of global digital content industry. In International Conference on Information and Management Engineering (pp. 132-142). Springer, Berlin, Heidelberg.

John, K. K., Adarsh, S. N., \& Pattali, V. (2020, December). Workers to super workers: A brief discussion on important technologies for industry 5.0 manufacturing systems. In AIP Conference Proceedings (Vol. 2311, No. 1, p. 070025). AIP Publishing LLC.

Katzenbach, C., \& Bachle, T. C. (2019). Defining Concepts of the Digital Society. Internet Policy Review, 8(4). https://doi.org/10.14763/2019.4.1430.

Hruška, L., Krajčík, V., \& Formánek, I. (2018). The conceptual model of collaborative economy. Scientific papers of the University of Pardubice. Series D, Faculty of Economics and Administration. 42/2018.

Levin, I., \& Mamlok, D. (2021). Culture and Society in the Digital Age. Information 2021, $12,68$. https://doi.org/10.3390/info12020068

Lin, S., Murphy, B., Clauer, E., Loewen, U., Neubert, R., Bachmann, G., Pai, M., \& Hankel, M. (2017). Architecture Alignment and Interoperability An Industrial Internet Consortium and Plattform Industrie 4.0 Joint Whitepaper, Retrieved from https://www.iiconsortium.org/pdf/JTG2_Whitepaper_final_20171205.pdf

Liu, W., \& McKibbin, W. J. (2020). Global macroeconomic impacts of demographic change. World Economy. https://doi.org/10.1111/twec.13166.

Lupan, M. \& Carmen, N. (2006). Some Aspects Regarding The Global Economy, pp. 221-25 in Business Excellence, editoval Bratianu, C and Lixandroiu, D and Pop, NA. Minist Educ \& Res; Acad Econ Studies; Transilvania Univ Brasov; Pro Ideas srl.

Marin, A. A. (2018). The Human Capital and Digital Society. Pp. 2428-44 In Vision 2020: Sustainable Economic Development And Application Of Innovation Management, editoval Soliman, KS. Int Business Informat Management Assoc.

Min, Z. (2013). 9. Structural Changes of Global Economy and New Challenges of Emerging Economy. In China and the World (pp. 155-177). Brill.

Mladek, J. (2017). Czech Economy And Industry 4.0, pp. 82-89 in Proceedings Of The 10th International Conference European Entrepreneurship Forum 2016: Economic Growth And Economic Policy, editoval Hamernikova, B. European Movement Czech Republ; Evropske Forum Podnikani.

Nahavandi, S. (2019). Industry 5.0-A Human-Centric Solution. Sustainability, 11 (16), 4371. https://doi.org/10.3390/su11164371.

OECD Digital Economy Outlook (2015). OECD Publishing, Paris, Retrieved from: https://www.oecd.org/digital/oecd-digital-economy-outlook-2015-9789264232440-en.htm

OECD Secretariat (Directorate for Science, Technology and Innovation) (2015). Enabling The Next Production Revolution: Issues Paper, OECD, Paris, 2015. Retrieved from: https://www.oecd.org/officialdocuments/publicdisplaydocumentpdf/?cote=DSTI/IND(2015)2\&docLangu $\underline{\text { age }=\text { En }}$

Okeme, P. A., Skakun, A. D., \& Muzalevskii, A. R. (2021, January). Transformation of Factory to Smart Factory. In 2021 IEEE Conference of Russian Young Researchers in Electrical and Electronic Engineering (ElConRus) (pp. 1499-1503). IEEE.

Özdemir, V., \& Hekim, N. (2018). Birth of industry 5.0: Making sense of big data with artificial intelligence, "the internet of things" and next-generation technology policy. Omics: a journal of integrative biology, 22(1), 65-76. https://doi.org/10.1089/omi.2017.0194.

Pomffyová, M., Rostašová, M., \& Krajčík, V. (2018). The Role of Spin-Off Companies in the Technology Transfer and IS Management Potential in Developing a Sharing Economy. In Industry 4.0-Impact on Intelligent Logistics and Manufacturing. IntechOpen. . https://doi.org/10.5772/intechopen.81441.

Salimova, T., Vukovic, N., \& Guskova, N. (2020). Towards sustainability through Industry 4.0 and Society 5.0. International Review, (3-4), 48-54.

Salimova, T., Vukovic, N., Gruskova, N., \& Krakovskaya, I. (2021). Industry 4.0 and Society 5.0: Challenges and Opportunities, The Case Study of Russia. Smart Green City, 17(4).

Sanders, A., Elangeswaran, C., \& Wulfsberg, J. P. (2016). Industry 4.0 implies lean manufacturing: Research activities in industry 4.0 function as enablers for lean manufacturing. Journal of Industrial Engineering and Management (JIEM), 9(3), 811-833. https://doi.org/10.3926/jiem.1940

Sharifi, A., Ahmadi, M., \& Ala, A. (2021). The impact of artificial intelligence and digital style on industry and energy post-COVID-19 pandemic. Environmental Science and Pollution Research, 1-21. https://doi.org/10.1007/s11356-021-15292-5. 
Shi, Z., Xie, Y., Xue, W., Chen, Y., Fu, L., \& Xu, X. (2020). Smart factory in Industry 4.0. Systems Research and Behavioral Science, 37(4), 607-617. https://doi.org/10.1002/sres.2704.

Šimanová, J., \& Kocourek, A. (2019). Readiness of Czech Regions for Industry 4.0. In Proceedings of the 14th International Conference Liberec Economic Forum 2019. Technical University of Liberec.

Sochul'akova, J. \& Kral'ova, K. (2020). Position Of Smes In The Context Of Industry 4.0”. S. 364-69 In Vplyv Industry 4.0 Na Tvorbu Pracovnych Miest 2019, editoval Kordos, M. Sova Digital; Vetropack; Univ Trenchinensis, Fakulta Socialno Ekonomicky Vztahov; RUZ; MUZIKA; ZZKS; Sektorovo Riadene Inovacie; TREXiMA; Savanna Cafe.

Sommer, L. (2015). Industrial revolution-industry 4.0: Are German manufacturing SMEs the first victims of this revolution?. Journal of Industrial Engineering and Management, 8(5), 1512-1532.

Sufian, A. T., Abdullah, B. M., Ateeq, M., Wah, R., \& Clements, D. (2019, October). A roadmap towards the smart factory. In 2019 12th International Conference on Developments in eSystems Engineering (DeSE) (pp. 978-983). IEEE.

Švarc, J., Lažnjak, J., \& Dabić, M. (2020). The role of national intellectual capital in the digital transformation of EU countries. Another digital divide?.Journal of Intellectual Capital. 22(4):768-91. https://doi.org/10.1108/JIC-02-2020-0024.

Syska, A., \& Lièvre, P. (2016). Illusion 4.0. Deutschlands naiver Traum von der smarten Fabrik. Herrieden.

Verhovnik, J., \& Duh, E. S. (2021). The importance of Industry 4.0 and digital transformation for SMEs. Elektrotehniski Vestnik, 88(3), 147-149.

Xu, X., Lu, Y., Vogel-Heuser, B., \& Wang, L. (2021). Industry 4.0 and Industry 5.0-Inception, conception and perception. Journal of Manufacturing Systems, 61, 530-535. https://doi.org/10.1016/j.jmsy.2021.10.006. 